\title{
Demir Eksikliği Anemisi Nedeniyle Gastroskopi ve Kolonoskopi Yapılan Hastalarda Malignite Sıklığının Değerlendirilmesi
}

@ (iD) Uzm. Dr. Mustafa Zanyar Akkuzu1, @ (iD Prof. Dr. Orhan Sezgin ${ }^{1}$, @ (iD Doç. Dr. Serkan Yaraş ${ }^{1}$, @ (iD) Doç. Dr. Osman Özdoğan ${ }^{1}$, @ (iD) Uzm. Dr. Hatice Rızaoğlu Balcı ${ }^{1}$ @ (iD Uzm. Dr. Ferzan Aydın", @ (iD) Doç. Dr. Enver Üçbilek ${ }^{1}$ @ (iD) Prof. Dr. Engin Altıntaş ${ }^{1}$, @ (iD) Prof. Dr. Fehmi Ateş ${ }^{1}$

${ }^{1}$ Mersin Üniversitesi Tıp Fakültesi Gastroenteroloji Bilim Dalı, Mersin, Türkiye

Öz

Demir Eksikliği Anemisi Nedeniyle Gastroskopi ve Kolonoskopi Yapılan Hastalarda Malignite Sıklı̆̆ının Değerlendirilmesi

Amaç: Anemilerin çoğu gibi demir eksikliği anemisi de kendi bașına bir hastalık değildir ve etiyolojinin her hastada araștırılıp ortaya konması gerekmektedir. Demir eksikliği anemisinde yaș gruplarına göre etyolojik nedenlerin sıklığı değişmektedir. Demir eksikliği anemisinin en önemli sebebi premenapozal kadınlarda menstrüel kanamalar iken; postmenapozal kadınlar ve erișkin erkeklerde gastrointestinal sistemden olan kronik kan kayıpları olușturmaktadır. Bu çalışmada demir eksikliği nedeniyle kliniğimizde gastroskopi ve kolonoskopi uygulanan hastaların malignite sıklığının değerlendirilmeşi amaçlandı.

Yöntem: 2018 Aralık ve 2019 Temmuz ayları arasında demir eksikliği anemisi etiyolojisi taraması nedeniyle gastroskopi ve kolonoskopi yapılan hastalar çalıșmaya alındı. Kolonoskopi uygun hazırlık sonrası terminal ileumun değerlendirilmesini içerecek șekilde uygulanmıștı. Hastaların yaş, cinsiyet, anamnez bilgileri ve işlem sonuçları dosyaları araştırılarak geriye dönük olarak incelendi.

Bulgular: Bu sürede demir eksikliği anemisi nedeniyle 142 hastada kolonoskopi yapılmıștı. Olguların 130'una gastroskopi de uygulanmıștı.

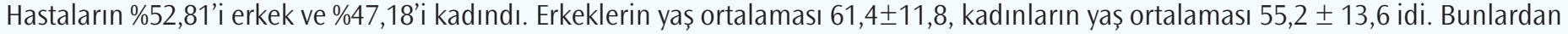
$\% 15,5$ hastada kolonda polip saptanmış olup \%80,5'i adenomatöz polipti. \%7 hastada kolonda karsinom saptandı. Bu hastaların toplam \%57,7'ünde de mide adenokanseri, ülser, gastrit, özofajit, özofagus varisi, polip ve özofajit gibi anemiyi açıklayabilecek bir patoloji saptandı. Toplam \%64,8 hastada anemiyi açıklayabilecek bir endoskopik bulgu mevcuttu.

Sonuç: Demir eksikliği anemisi laboratuvar çalıșmaları ile doğrulandıktan ve diyete bağlı demir eksikliği, demir ihtiyacında artış ve gastrointestinal sistem dışı kan kaybına bağlı anemi dışlandıktan sonra, gastrointestinal traktüsün endoskopik incelemesine geçilmelidir. Bu çalışmada hastaların \%15,5’inde kolonda polip, \%7,04'ünde adenokarsinom tespit edildi. Hastaların \%0,7'sında midede adenokarsinom tespit edildi. Bu da demir eksikliği anemisi etiyolojisinde hem gastroskopi hem de kolonoskopinin önemini göstermektedir.

Anahtar Kelimeler: Demir Eksikliği Anemisi, Kolonoskopi, Endoskopi, Gastroskopi, Tarama

\section{Abstract}

Evaluation of Frequency of Malignancy in Patients Undergoing Colonoscopy Due to Iron Deficiency Anemia

Objective: Like most anemias, iron deficiency anemia is not a disease in itself and its etiology needs to be investigated and revealed in each patient. The frequency of etiological causes varies according to age groups in iron deficiency anemia. While the most important cause of iron deficiency anemia is menstrual bleeding in premenopausal women; It causes chronic blood loss from the gastrointestinal system in postmenopausal women and adult men. In this study, it was aimed to evaluate the malignancy prevalence of patients who underwent gastroscopy and colonoscopy due to iron deficiency.

Method: The study included patients who underwent gastroscopy and colonoscopy for iron deficiency anemia etiology screening between December 2018 and July 2019. Colonoscopy was performed after appropriate preparation to be evaluated in the terminal ileum. The patients' age, gender, anamnesis information and procedure results files were examined retrospectively.

Results: During this period, colonoscopy was performed in 142 patients due to iron deficiency anemia. Gastroscopy was also performed on 130 of them. $52.81 \%$ of the patients were men and $47.18 \%$ were women. The mean age of men was $61.4 \pm 11.8$, and the mean age of women was $55.2 \pm 13.6$. Of these, $15.5 \%$ of patients had polyps in the colon and $80.5 \%$ of them were adenomatous polyp. Carcinoma in the colon was detected in $7 \%$ of the patients. In a total of $57.7 \%$ of these patients, a pathology that could explain anemia such as gastric adenocarcinoma, ulcer, gastritis, esophagitis, esophageal varices, polyps and esophagitis was detected. A total of $64.8 \%$ patients had an endoscopic finding that could explain anemia.

Conclusion: Endoscopic examination of the gastrointestinal tract should be started after iron deficiency anemia is confirmed by laboratory studies and after excluding anemia due to dietary iron deficiency, increased iron requirement and extra-gastrointestinal blood loss. In this study, we detected polyps in the colon in 15.5\% of the cases, and adenocarcinoma in $7.04 \%$ of the patients. In the stomach, $0.7 \%$ of the patients were found to have adenocarcinoma. This shows the importance of both gastroscopy and colonoscopy in the etiology of iron deficiency anemia.

Keywords: Iron Deficiency Anemia, Colonoscopy, Endoscopy, Gastroscopy, Scanning

Yazıșma Adresi/Address for Correspondence: Uzm. Dr. Mustafa Zanyar Akkuzu

Email: zanyarakkuzu@gmail.com

ORCID iD: 0000-0002-9908-6881 


\section{Gíriș}

Dünya Sağlık Örgütü'nün (WHO) tanımlamasına göre anemi; erișkinler için hemoglobin değerinin erkeklerde $13 \mathrm{~g} /$ dl'nin, kadınlarda $12 \mathrm{~g} / \mathrm{dl}$ ' nin altı olarak tanımlanır. Demir eksikliği anemisi en sık görülen anemi türüdür ve kadınlarda erkeklerden daha fazla görülmektedir (1). Gelişmiş ülkelerde DEA prevalansı \%8 civarındadır (2).

Anemilerin çoğu gibi demir eksikliği anemisi de kendi başına bir hastalık değildir ve etiyolojinin her hastada araștırılıp ortaya konması gerekmektedir. Demir eksikliği anemisi yaş gruplarına göre etyolojik nedenlerin sıklığı değișmektedir. Demir eksikliği anemisinin en önemli sebebi premenapozal kadınlarda menstrüel kanamalar iken; postmenapozal kadınlar ve erişkin erkeklerde ise gastrointestinal sistemden olan kronik kan kayıpları oluşturmaktadır (3). Üst ve alt endoskopik ișlem yapılan hastaların \%48-71'inde DEA'nın nedeni bulunmuş; açıklanamayan olgularda ise tekrar endoskopik işlem yapılan olguların \%35'inde gözden kaçan lezyonların tespit edildiği bildirilmiştir. Hatta son zamanlarda endoskopik incelemelere rağmen devam eden anemide ince bağırsağın da incelenmesi (kapsül endoskopi veya çift balon enteroskopisi) ile DEA'nın tanısında başarı \%61-74'lere çıkmıștır (4).

Bu çalışmada kliniğimizde demir eksikliği nedeniyle gastroskopi ve kolonoskopi uygulanan hastaların sonuçlarının sunulması amaçlanmıştır.

\section{METOT}

Mersin Üniversitesi Tıp Fakültesi Hastanesi GastroenteroIoji Bölümünde 2018 Aralık ve 2019 Temmuz tarihleri arasında demir eksikliği anemisi etiyoloji taraması nedeniyle gastroskopi ve kolonoskopi uygulanan hastalar çalıșmaya alındı. Hasta onamı işlem esnasında alınmış olup verileri retrospektif olarak değerlendirildi. Hastaların yaş, cinsiyet, anamnez bilgileri ve endoskopik sonuçlarına dosyaları araștırılarak geriye dönük olarak ulaşıldı. Çalışmaya hematolojik ve onkolojik malignite nedeniyle takip ve tedavi edilen hastalar, gastrointestinal kanama ile başvuran hastalar, verileri eksik olan hastalar, 18 yaş altı olan hastalar, aktif enfeksiyon ve sepsisi olan hastalar, kronik renal ve karaciğer yetmezliği olan hastalar, daha önceden tespit edilmiș malignitesi, geçirilmiș mide ve bağırsak rezeksiyonu, bilinen inflamatuar bağırsak hastaı̆̆ı, malabsorbsiyonu, bağırsak polibi ve divertikülozisi olan hastalar, yani bilinen herhangi bir kronik hastalığı olanlar dahil edilmedi. Anemi için hemoglobin değeri kadınlarda $<12$ $\mathrm{g} / \mathrm{dl}$, erkeklerde $<13 \mathrm{~g} / \mathrm{dl}$, demir eksikliği için transferrin satürasyonu $\leq \% 15$ olan hastalar çalıșmaya alındı. Kolonoskopi uygun hazırlık sonrası terminal ileumun değerlendirilmesini içerecek șekilde uygulanmıştı.
Tablo 1. Kolonoskopide Polip Saptanan Hastalarm Özellikleri

\begin{tabular}{|c|c|c|}
\hline Toplam Hasta Sayısı: 22 & \multicolumn{2}{|c|}{ Toplam Polip Sayısı: 36} \\
\hline \multirow{6}{*}{ Lokalizasyon } & İnen Kolon & $\% 33,3$ \\
\hline & Rektum & $\% 22,2$ \\
\hline & Çוkan kolon & $\% 22,2$ \\
\hline & Transvers Kolon & $\% 11,1$ \\
\hline & Sigmoid Kolon & $\% 9,3$ \\
\hline & Çekum & $\% 2,8$ \\
\hline \multirow{5}{*}{ Polip Çapları } & $<0,5 \mathrm{~cm}$ & $\% 58,3$ \\
\hline & $1 \mathrm{~cm}$ & $\% 16,7$ \\
\hline & $1,5 \mathrm{~cm}$ & $\% 11,1$ \\
\hline & $4 \mathrm{~cm}$ & $\% 8,3$ \\
\hline & $3 \mathrm{~cm}$ & $\% 5,5$ \\
\hline \multirow{5}{*}{ Histopatolojik Tipleri } & Tübüler adenom \%50 & $\% 50$ \\
\hline & Tübülovillöz adenom \%30,55 & $\% 30,5$ \\
\hline & Hafif kronik inflamasyon & $\% 8,3$ \\
\hline & Hiperplastik polip & $\% 8,3$ \\
\hline & İnflamatuar polip & $\% 2,8$ \\
\hline Displazi Dereceleri & \multicolumn{2}{|c|}{ \%80,55’i düşük dereceli displazi } \\
\hline \multirow{3}{*}{ Sigara ve Alkol } & \multicolumn{2}{|c|}{ 6'sı > 25 yıl/paket sigara kullanıp bırakma } \\
\hline & \multicolumn{2}{|c|}{ 5’i > 25 paket/yıl aktif sigara kullanma } \\
\hline & \multicolumn{2}{|c|}{ 1’i> 50 gr/gün alkol öyküsü } \\
\hline
\end{tabular}

Tablo 2. Kolonoskopide Malignite Saptanan Hastalarm Özellikleri

\begin{tabular}{|c|c|c|}
\hline Histopatolojik Tip & \multicolumn{2}{|c|}{ Adenokarsinoma } \\
\hline \multirow{5}{*}{ Lokalizasyon } & Rektum & $\% 30$ \\
\hline & Sigmoid kolon & $\% 20$ \\
\hline & Transvers kolon & $\% 20$ \\
\hline & İnen Kolon & $\% 10$ \\
\hline & Çekum & $\% 10$ \\
\hline \multirow{2}{*}{ Sigara ve Alkol } & \multicolumn{2}{|c|}{ 3’ü> 20 yıl/paket sigara } \\
\hline & \multicolumn{2}{|c|}{ 1’i <30 dr/gün alkol } \\
\hline \multirow{3}{*}{ BMI } & \multicolumn{2}{|c|}{ 25-30 arası yedi hasta } \\
\hline & \multicolumn{2}{|c|}{$<25$ iki hasta } \\
\hline & \multicolumn{2}{|c|}{$>30$ bir hasta } \\
\hline
\end{tabular}

\section{İstatistiksel İnceleme}

İstatistiksel analizlerin hesaplanmasında SPSS 21.0 for Windows programı kullanıldı. Çalışma verileri değerlendirilirken tanımlayıcı istatistiksel metotlar (Ortalama, Standart sapma) kullanıldı. 


\begin{tabular}{|c|c|c|c|}
\hline & & Sayı (n) & Yüzde (\%) \\
\hline \multirow{3}{*}{ Helicobakter pylori } & Bakılmamıș & 52 & 36 \\
\hline & Pozitif & 36 & 25,4 \\
\hline & Negatif & 54 & 38 \\
\hline \multirow{3}{*}{ İntestinal Metaplazi } & Bakılmamıș & 52 & 36 \\
\hline & Pozitif & 13 & 9,2 \\
\hline & Negatif & 77 & 54,2 \\
\hline \multirow{3}{*}{ Çölyak } & Bakılmamış & 125 & 88 \\
\hline & Pozitif & 4 & 2,8 \\
\hline & Negatif & 13 & 9,2 \\
\hline \multirow{10}{*}{ Endoskopik Patolojiler } & Bakılmamıș & 12 & 8,5 \\
\hline & Hiperplastik Polip & 5 & 3,5 \\
\hline & $\begin{array}{l}\text { Ülser (3 Duodenum } \\
3 \text { Mide) }\end{array}$ & 6 & 4,2 \\
\hline & $\begin{array}{l}\text { Adenokanser } \\
\text { (Kardiada) }\end{array}$ & 1 & 0,7 \\
\hline & Özofagus Varisi & 4 & 2,8 \\
\hline & Barret Özofagusu & 1 & 0,7 \\
\hline & Özofajit & 6 & 4,2 \\
\hline & Schatzki halkası & 1 & 0,7 \\
\hline & Hiatal Herni & 6 & 4,2 \\
\hline & $\begin{array}{l}\text { Kronik Aktif Gastrit } \\
\text { (Patolojik Tanı) }\end{array}$ & 60 & 42,3 \\
\hline
\end{tabular}

\section{BULGULAR}

Toplam bu süre zarfında 574 hastanın 142'sinde (\%24,73) demir eksikliği anemisi etiyolojisi nedeniyle kolonoskopi istenmiști. Hastaların 75’i (\%52,8) erkek hasta, 67'si $(\% 47,2)$

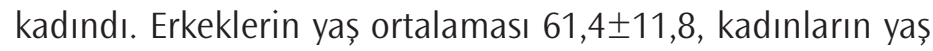
ortalaması 55,2 $\pm 13,6$ idi. Olguların 130'una gastroskopi yapılmıştı. Kolonoskopi normal olmasına rağmen gastroskopi yapılmamış $8(\% 5,6)$ hasta mevcuttu. $60(\% 42,2)$ hastada anemiyi açıklayabilecek endoskopik bulgu yoktu ve 110'unda $(\% 77,5)$ kolonda polip veya karsinom mevcut olmayıp anemiyi açıklayabilecek kolonoskopik bulgu yoktu. Hastaların \%28,2'sinde hem kolonoskopi normaldi hem de egastroskopide anlamlı bir özellik yoktu. Ancak toplam \%64,8 hastada anemiyi açıklayabilecek ya gastroskopik bulgu ya da kolonoskopik bulgu mevcuttu.

Kolonoskopide $22(\% 15,5)$ hastada polip, $10(\% 7,04)$ hastada da karsinom tespit edildi. Polip tespit edilen hastaların polip sayılarına bakıldığında 16 hastada bir adet, üçünden iki adet, birinden üç adet, birinden beş adet ve birinden de altı adet polip çıkarılmıștı. Toplam 22 hastada 36 adet polip mevcuttu. Poliplerin çaplarına bakıldığında 21'inde $(\% 58,3)$ $<0,5 \mathrm{~cm}$ çaplı dimunitif polip, $1 \mathrm{~cm}$ çaplı altı $(\% 16,7)$ adet, $1,5 \mathrm{~cm}$ çaplı dört $(\% 11,1)$ adet, $4 \mathrm{~cm}$ çaplı üç $(\% 8,3)$ adet, 3 cm çaplı iki $(\% 5,5)$ adet polip mevcuttu. Poliplerin displazi derecelerine bakıldığında ise $29^{\prime}$ unda $(\% 80,5)$ hafif derecede displazi derecesi mevcuttu.

Toplam polip lokalizasyonlarını incelediğimizde; 12'sinin $(\% 33,3)$ inen kolonda, 8'inin $(\% 22,2)$ rektumda, 8'inin $(\% 22,2)$ çıkan kolonda, 4'ünün $(\% 11,1)$ transvers kolonda, 3'ünün $(\% 9,3)$ sigmoid kolonda ve 1 'inin de $(\% 2,8)$ çekumda olduğu tespit edildi. Poliplerin histolojik tipleri incelendiğinde 29 $(\% 80,5)$ adet adenomatöz polip, 18’i (\%50) tübüler adenom, 11 ’i $(\% 30,5)$ tübülovillöz adenom, 3’ü $(\% 8,3)$ hafif kronik inflamasyon ve refeneratif değişiklikler içerdiği, 3’ü $(\% 8,3)$ hiperplastik polip ve 1'i $(\% 2,8)$ inflamatuar polip șeklinde raporlanmıștı. Bunların hiçbirinin ailesinde kolon ca veya polip öyküsü yoktu. Sadece birinde 50 gr/günden fazla alkol kullanım öyküsü, altısının 25 paket/yıldan fazla sigara kullanıp bırakma öyküsü, beșinin de 25 paket/yıl dan fazla süren aktif sigara kullanım öyküsü mevcuttu (Tablo 1).

Kolon kanseri tespit edilenlerin lokalizasyonlarına baktığımızda 3'ü (\%30) rektumda, 2'si (\%20) sigmoid kolonda, 2'si (\%20) transvers kolonda, 1’i (\%10) inen kolonda, 1’i de (\%10) çekumda tespit edilmiști. Kolon ca histolojik tipine bakıldığında hepsinde adenokarsinoma tespit edilmiști. Bunların hiçbirinin ailesinde kolon ca öyküsü mevcut değildi. Bunlardan üçünde 20 yıldan fazla sigara içme öyküsü, birinde de $30 \mathrm{dr} /$ gün'den az alkol kullanım öyküsü mevcuttu. Diğerlerinde sigara ve alkol kullanım öyküsü yoktu. Hastaların BMi'sine bakıldı ̆̆ında birinin $>30$, ikisinin $<25$ ve diğerlerinin de $25-30$ arasında olduğu görüldü (Tablo 2).

Gastroskopi yapılan hastaların 1'inde kardiada adenokanser ve 1'inde barret özofagusu tespit edilmiști. Hastaların 60 'ında patolojik olarak tanı konulmuş kronik aktif gastrit, 6'sında ülser, 5 'inde hiperplastik polip, 4'ünde özofagus varisi, 6'sında özofajit ve 6'sında da hiatal herni mevcuttu. Hastaların 17'sinde çölyak açısından duodenum biopsisi alınmış olup 4 hastada çölyak hastalığı tespit edilmiști. 90 hastadan Helicobakter pylori ve intestinal metaplazi için biopsi alınmıștı. Bunların 36'sında Helicobakter pylori, 13'ünde intestinal metaplazi mevcuttu (Tablo 3). Toplam \%64,8 hastada anemiyi açıklayabilecek bir endoskopik bulgu mevcuttu.

\section{TARTIȘMA VE SONUÇ}

Demir eksikliği anemisi laboratuvar çalıșmaları ile doğrulandıktan ve diyete bağlı demir eksikliği, demir ihtiyacında artış ve gastrointestinal sistem dıșı kan kaybına bağlı anemi dıșlandıktan sonra, gastrointestinal traktüsün endoskopik incelemesine geçilmelidir. Demir eksikliğinin iki önemli nede- 
ni kronik kan kaybı ve demir emilim bozukluklarıdır. Her iki durum da gastrointestinal sistemi yakından ilgilendirmekte olup demir eksikliği nedeni ile yapılan gastrointestinal uygulamalarda farklı hasta gruplarında \%43-86'sında nedenin gastrointestinal kaynaklı olduğu saptanmıștır (5-11).

Demir eksikliği olan hastalarda gastrointestinal sistem kanserleri ilk akla gelen tanılardandır. Demir eksikliği anemisi olan hastalarda yapılan gastrointestinal sistem endoskopik incelemelerinde malignite saptanma oranı \%6 ile \%13 arasında değișen oranlarda bildirilmiștir (5-11). Ülkemizde demir eksikliği anemisi nedeniyle yapılan bir çalıșmada gastroskopide \%3,81 oranında ve kolonoskopide \%8,6 oranında malignite saptandığı bildirilmiștir (5). Ülkemizde yapılan diğer bir çalıșmada demir eksikliği anemisi nedeniyle tetkik edilen hastalarda üst gastrointestinal endoskopisi yapılan hastaların \%0,9'unda, alt gastointestinal sistem endoskopi yapılan hastaların \%4,7'sinde adenokanser tanısı konmuștur. Yine bu çalıșmada kolonoskopide polip saptanma sıklı̆̆ı \%45 olarak bildirilmiștir (12). Ösofagogastroskopinin tanısal yararı kolonoskopiden yüksek bulunmakla birlikte (13-15), özellikle yașlılarda, anemiyi açıklayacak benign üst gastrointestinal lezyon saptanması halinde dahi kolonoskopik inceleme gereklidir $(14,16,17)$. Benign üst gastrointestinal lezyon saptanan hastalarda önemli oranda kolona ait malignite saptanması tüm kolon incelemesini zorunlu kılmaktadır (14).

Çalıșmaya dahil edilen hastalarda kolonoskopide \%15,5 hastada polip, \%7 hastada da adenokarsinom tespit edilmiş olup Tablo 1 ve 2'de ayrıntılı özelliklerine değinilmiștir. Toplamda \%22,54 oranında kolonda neoplastik lezyon (polip veya kanser) saptanmıștır. Gastroskopide en sık rastlanan lezyon gastrit idi $(\% 42,3)$. Ayrıca gastroskopide \%0,7 oranında adenokanser ve \%0,7 oranında premalign olan barret özofagusu saptandı. \%3,5 oranında polip, \%2,8 oranında çölyak hastalığı ve \%2,8 oranında özofagus varisi ve karaciğer sirozu saptanmıștır. Bu oranlar da her iki ișlemin birlikte yapılması gerektiğini göstermektedir. Ayrıca sadece 17 hastadan çölyak açısından biopsi alınmasına rağmen 4'ünde $(\% 23,5)$ çölyak pozitif çıkmış olması demir eksikliği anemisi etyolojisinin araștırılmasında rutin duodenal biopsinin yapılması gerektiğini düșündürmektedir.

Sonuç olarak, DEA'nın sebebi araștırılırken, özellikle gastrointestinal kanaldan kaynaklanan bir patoloji düșünülüyorsa, altta yatan pek çok sebebin olabileceği unutulmamalıdır. Bu sebepler içinde en önemli hastalık olan maligniteler önemli yer tutmaktadır. Günümüzde kolorektal kanser sıklığının gastrik kanserden daha fazla olduğu düşünüldügüüne öncelikle kolonoskopi yapılması, eğer kolonoskopi negatif çıkarsa gastroskopi yapılması gerektiği öngörülmektedir.

\section{BILDIRIMLER}

Değerlendirme

Dış danışmanlık

Çıkar Çatıșması

Yazarlar bu makale ile ilgili herhangi bir çıkar çatışması bildirmemişlerdir.

Finansal Destek

Yazarlar bu makale ile ilgili herhangi bir malî destek kullanımı bildirmemișlerdir.

\section{Etik Beyan}

Bu çalıșma için Mersin Üniversitesi Tıp Fakültesi Klinik Araștırmalar Etik Kurulundan 22/01/2020 tarih ve 44 numaraIı karar yazısı ile izin alınmış olup Helsinki Bildirgesi kriterleri göz önünde bulundurulmuștur.

\section{KAYNAKLAR}

1. World Health Organization. Nutritional Anemias: Report of a WHO Scientific Group. WHO Technical Reports Series 405. Geneva, Switzerland: World Health Organization, 1968.

2. Provan D. Mechanism and management of iron deficiency anemia. Br J Haematol 1999;105(Suppl 1):19-26.

3. Goddard AF, James MW, Mc Intyr AS, Scott BB. Guidelines for the management of iron deficiencyanemia. Gut. 2011;60(10):130916. https://doi.org/10.1136/gut.2010.228874.

4. Bull-Henry K, Al-Kawas FH. Evaluation of occult gastrointestinal bleeding. Am Fam Physician 2013;87:430-6.

5. Çetinkaya ZA, Sezikli M, Güzelbulut F, ve ark. Demir eksikliği anemili hastalarda gastrointestinal endoskopik inceleme sonuçları. Dicle Tıp Dergisi 2011; 38:155-59. https://doi. org/10.5798/diclemedj.0921.2011.2.0006.

6. James MW, Chen C-M, Goddard WP, et al. Risk factors for gastrointestinal malignancy in patients with iron-deficiency anaemia. Eur J Gastroenterol Hepatol 2005;17:1197-203. https://doi.org/10.1097/00042737-200511000-00008.

7. McIntyre AS, Long RG. Prospective survey of investigations in outpatients referred with iron deficiency anaemia. Gut 1993;34:1102- 7. https://doi.org/10.1136/gut.34.8.1102.

8. Rockey DC, Cello JP. Evaluation of the gastrointestinal tract in patients with iron-deficiency anemia. N Engl J Med 1993;329:1691- 5. https://doi.org/10.1056/ NEJM199312023292303.

9. Kepczyk T, Kadakia SC. Prospective evaluation of gastrointestinal tract in patients with iron-deficiency anemia. Dig Dis Sci 1995;40:1283-99. Ho CH, Chau WK, Hsu HC, et al. Predictive risk factors and prevalence of malignancy in patients with iron deficiency anemia in Taiwan. Am J Hematol 2005;78:108-12. https://doi.org/10.1002/ajh.20260.

10. Ioannou GN, Rockey DC, Bryson CL, et al. Iron deficiency and gastrointestinal malignancy: a population-based cohort study. Am J Med 2002;113:276-80. https://doi.org/10.1016/ S0002-9343(02)01214-7. 
11. Majid S, Salih M, Wasaya R, Jafri M. Predictors of gastrointestinal lesions on endoscopy in iron deficiency anemia without gastrointestinal symptoms. BMC Gastroenterol 2008;8:52. https://doi.org/10.1186/1471-230X-8-52.

12. Ünal ÜH, Fidan C, Korkmaz M, Selçuk H. Demir eksikliği olan hastalarda gastrointestinal sistem endoskopi bulguları. Akademik Gastroenteroloji Dergisi 2012; 3:113-16.

13. Moses PL, Smith RE: Endoscopic evaluation of iron deficciency anemia. A guide to diagnostic strategy in older patients. Postgroduote medicine, 1995 98(2): 213-216, 219, 222-4. https://doi.org/10.1080/00325481.1995.11946039.

14. Cook I J, Pavli P, Riley JW, Goulston KJ, Dent OF: Gastrointestinal investigation of iron deficiency anemia. British Medical
Journal 1986 Vol 292: 1380-1382. https://doi.org/10.1136/ bmj.292.6532.1380.

15. Gordon SR, Smith RE, Power GC: The role of iron deficiency anemia in patients over the age of 50. Am J Gastroenterol 1994; 89 (II): 1963-1967.

16. Zuckerman G, Benitez J: A prospective study of bidirectional endoscopy (Colonoscopy and EGD) in the evaluation of patients with occult gastrointestinal bleeding. AM J Gastrointestinal 1992; 87: 62-66.

17. My Intyre AS, Long RG: Prospective survey of investigations in outpatient with iron deficiency anemia. Gut 1993; 34: 11021107. https://doi.org/10.1136/gut.34.8.1102. 